\title{
Comparison of simultaneous bilateral versus unilateral total knee replacement on pain levels and functional recovery
}

\author{
Ahmad H. Alghadir ${ }^{1}$, Zaheen A. Iqbal ${ }^{1}$, Shahnawaz Anwer ${ }^{1,2^{*}}$ and Dilshad Anwar ${ }^{3,4}$
}

\begin{abstract}
Background: Total knee replacement is a common operative procedure to improve pain, function, and quality of life in patients with end stage knee osteoarthritis. The current study aimed to compare simultaneous bilateral versus unilateral total knee replacement on pain intensity and recovery of function.

Methods: A total of 80 patients (bilateral 50, unilateral 30) aged 63.28 (9.4) years undergone total knee replacement participated in the current study. The participants were admitted for 5-7 days in the hospital. Participants in both the group received similar inpatient and outpatient physiotherapy sessions. Pain intensity and function capacity were assessed at baseline, day 7, and day 30 postoperatively using visual analogue scale and lower extremity functional scale, respectively. Repeated measures analysis of variance was used to analyze the data.

Results: Both groups showed a significant reduction of pain intensity (Day 0, mean 8.9, SD 1.0; Day 30, mean 2.2, SD 1.3 in bilateral total knee replacement; Day 0, mean 8.8, SD 1.1; Day 30, mean 2.0, SD 1.5 in unilateral total knee replacement; $p<0.001$ ) and improvement in the functional capacity (Day 0, mean 16.2, SD 10.1; Day 30, mean 55.6, SD 14.6 in bilateral total knee replacement; Day 0, mean 19.1, SD 9.1; Day 30, mean 56.7, SD 15.8 in unilateral total knee replacement; $p<0.001)$ following total knee replacement at 30 days post-operatively. However, there was a non-significant difference noted between bilateral versus unilateral total knee replacement on the reduction of pain intensity (mean changes, 6.9 versus 6.8) and improvement in the functional capacity (mean changes, 39.4 versus 37.6) at 30 days post-operatively $(p>0.05)$.
\end{abstract}

Conclusion: Simultaneous bilateral total knee replacement was associated with a similar reduction of pain intensity and recovery of function compared to unilateral total knee replacement, suggesting the use of simultaneous bilateral total knee replacement in patients with bilateral knee osteoarthritis since its costs and rehabilitation process could be reduced compared to staged bilateral total knee replacement.

Keywords: Total knee arthroplasty, Bilateral, Unilateral, Pain, Function

\footnotetext{
* Correspondence: anwer_shahnawazphysio@rediffmail.com

${ }^{1}$ Rehabilitation Research Chair, College of Applied Medical Sciences, King Saud University, P.O.Box-10219, -11433, Riyadh, Saudi Arabia

2Department of Building and Real Estate, Hong Kong Polytechnic University, Kowloon, Hong Kong Special Administrative Region, Hong Kong

Full list of author information is available at the end of the article
}

C C The Author(s). 2020 Open Access This article is licensed under a Creative Commons Attribution 4.0 International License, which permits use, sharing, adaptation, distribution and reproduction in any medium or format, as long as you give appropriate credit to the original author(s) and the source, provide a link to the Creative Commons licence, and indicate if changes were made. The images or other third party material in this article are included in the article's Creative Commons licence, unless indicated otherwise in a credit line to the material. If material is not included in the article's Creative Commons licence and your intended use is not permitted by statutory regulation or exceeds the permitted use, you will need to obtain permission directly from the copyright holder. To view a copy of this licence, visit http://creativecommons.org/licenses/by/4.0/. The Creative Commons Public Domain Dedication waiver (http://creativecommons.org/publicdomain/zero/1.0/) applies to the data made available in this article, unless otherwise stated in a credit line to the data. 


\section{Background}

Total knee replacement (TKR) is a common operative procedure to improve pain, function, and quality of life in patients with severe grade knee osteoarthritis (OA) [1-4]. However, in many patients, bilateral TKR is required due to involvement of bilateral OA or other arthritis [5]. After 10 years of primary TKR, the incidence of TKR for contralateral knee for end-stage OA is 37\% [6]. Bilateral TKR could be performed simultaneously or in a staged. Simultaneous TKR is defined as the replacement of both knees in a single surgery. The major advantage of this surgery is that it requires only one hospital stay and rehabilitation period to recover both knees. However, previous studies have shown different perioperative risks between staged bilateral TKR and simultaneous bilateral TKR. While some studies indicate significantly higher mortality and morbidity risk with simultaneous bilateral TKR, other studies indicate reduced risk of mechanical malfunction and periprosthetic joint infection [7-10]. Additionally, an estimated cost of simultaneous TKR is almost half compared to staged bilateral TKR [11-13].

A few studies also investigated differences in pain and physical function following simultaneous bilateral or staged bilateral TKR. While one study indicates functional improvements following simultaneous bilateral TKR [14], another study reports positive outcome with respect to pain and physical function following staged bilateral TKR [15]. However, lack of control groups in these studies reduce the external validity of the results.

Many studies also compared perioperative outcomes and functional recovery between simultaneous bilateral versus unilateral TKR. For instance, Hart et al. [16] reported a reduced perioperative complication and was not correlated with more readmissions than unilateral TKR. Similarly, Borges et al. [17] reported no increase in complications or cost of simultaneous bilateral TKR surgery as compared to unilateral TKR surgery. Additionally, March et al. [18] compared the functional recovery and general health between simultaneous bilateral and unilateral TKR. They found better functional recovery and general health in simultaneous bilateral TKR group. However, participants in simultaneous bilateral TKR group were significantly younger than unilateral TKR group (70.9 versus $67.8 \mathrm{Y}, p=0.01$ ). While a previous study reported significantly better postoperative functional outcomes in simultaneous bilateral TKR group [19], a recent study reported no differences in the functional recovery between simultaneous bilateral and unilateral TKR [20]. Therefore, the present study aimed to assess whether simultaneous bilateral TKR results comparable improvement in pain intensity and functional recovery than unilateral TKR.

\section{Methods}

\section{Patients and procedure}

It was a series of prospective TKR cases performed by an Orthopedic surgeon in 3 years (2016 to 2019). This study compared two surgical procedures (e.g., simultaneous bilateral versus unilateral TKR) on pain and physical function. Pain intensity and recovery of function was assessed at baseline, day 7 , and day 30 post-operatively in patients with unilateral and simultaneous bilateral TKR. Institution ethics committee, RRC, King Saud University, Riyadh, Saudi Arabia approved the study. A written informed consent was taken from each patient. Inclusion criteria were as follow: (a) patients with end stage primary OA, (b) bilateral symptomatic knee OA, and (c) patients undergone first time for simultaneous bilateral or unilateral TKR. A total of 80 patients (bilateral, 50; unilateral, 30), undergoing TKR, were included in the current study. Patients with cardiopulmonary comorbidities and systemic illness such as chronic obstructive pulmonary disease, diabetes mellitus, cerebrovascular disease, peripheral vascular disease or active coronary artery disease were excluded for simultaneous bilateral or unilateral TKR [16]. All patients went through a preoperative medical evaluation to rule out high risk patients for simultaneous bilateral or unilateral TKR. The participants were admitted for 5-7 days in the hospital.

\section{Operative procedures}

Medial parapatellar approach was used for both unilateral and simultaneous bilateral TKR [21]. Vanguard ${ }^{\circ}$ knee system and the Triathlon ${ }^{\circ}$ Knee System prostheses were used. Knee joint was opened, osteophytes were removed, and resurfacing was done. Intramedullary drilling was done into femoral canal via intercondylar notch. Intramedullary distal resection guide was placed at 6 degrees of valgus and standard $9 \mathrm{~mm}$ distal resection was done to match with the distal thickness of the implant. Anterior referencing guide was used to measure femoral size. A chamfer was placed, and anterior, posterior, and oblique resections were made. Proximal tibial resection was done using extramedullary referencing guide and seven degrees of posterior slope was made. Then, tibia sling and broaching was done. Trial implant was placed, and stability and patellar tracking was assessed. When it was found satisfactory, implant placed, and cementing done. Wound was cleaned using Pulsed lavage technique [22]. Finally, closure was done in layers as suggested [23].

\section{Pre- and post-operative physiotherapy procedures}

Participants in both the group received similar inpatient (30 min, two sessions a day for 5 to 7 days as required) and outpatient (one session, 5 days a week for 3 weeks) physiotherapy sessions. Inpatient physiotherapy sessions 
comprised of strength training of lower extremity (e.g., hamstrings, quadriceps, and glutei muscles), mobility exercise, range of motion exercise, and gait training with walker. Outpatient physiotherapy sessions includes strength training of hamstrings, quadriceps, and glutei muscles, mobility exercise, range of motion exercise, and gait training and walking reeducation.

\section{Outcomes}

Pain intensity and function capacity were assessed at baseline, day 7 , and day 30 post-operatively using visual analogue scale (VAS) and lower extremity functional scale (LEFS), respectively. The VAS is a valid and reliable outcome measure to assess both acute and chronic pain [2426]. VAS is a $10 \mathrm{~cm}$ self-reported scale connected by 0 (indicates no pain at all) and 10 (indicates maximum pain). The 20-item LEFS is a reliable and valid functional outcome to assess lower-extremity function in patients undergoing knee or hip arthroplasty [27, 28]. The LEFS is a 5-point Likert scale ranging from 0 to 4 . Total possible scores range between 0 and 80 points, where a higher score indicates a better functional capacity.

\section{Statistical analysis}

Data was analyzed using IBM SPSS Statistics 21. The improvement in pain and functional scores during 1month between simultaneous bilateral versus unilateral TKR were assessed using the repeated measure ANOVA. Two variables for group (simultaneous bilateral versus unilateral TKR) and three variables for time ( 0 day versus 7 day versus 30 day) were used. A value of $p<0.05$ was considered for the statistical significance. The sample size was calculated using G*Power version 3.1.9.4. The required sample size for detecting an effect of 0.25 with $80 \%$ power and 0.05 level of significance in comparison of two treatment group ((simultaneous bilateral versus unilateral TKR) and three level of measurements (baseline, day 7, day 30) was 86 . However, in the current study, only 80 patients were included.

\section{Results}

Table 1 details the participant's characteristics. Mean age was 61.8 (SD, 9.2) and 65.7 (SD, 9.4) years in simultaneous bilateral TKR and unilateral TKR group, respectively. Both groups showed a significant reduction of pain intensity and improvement in the functional capacity following TKR at 30 days post-operatively $(p<$ 0.001) (Table 2). However, there was a non-significant difference noted between simultaneous bilateral versus unilateral TKR on reduction of pain intensity and improvement in the functional capacity at 30 days postoperatively $(p>0.05)$ (Figs. 1 and 2).

\section{Discussion}

The current study aimed to compare simultaneous bilateral versus unilateral TKR on pain intensity and recovery of function at 30-days postoperatively. Results of the current study indicated that both groups showed a significant pain relief and improved function after TKR at 30 days post-operatively. There was no significant difference noted between simultaneous bilateral versus unilateral TKR on pain intensity and recovery of function.

Some studies indicate that simultaneous bilateral TKR surgery reduces rehabilitation time and have no additional risk for postoperative complications compared to unilateral TKR [29-32, 32-35]. Additionally, the patient satisfaction scores, and functional outcomes are comparable, or better, in patients undergoing bilateral TKR than unilateral TKR, and this achieves without any additional medical costs $[18,29,18,32]$. While other studies reported statistically insignificant differences in pain reduction and functional recovery between bilateral versus unilateral TKR $[29,33,32,36]$, many studies indicated an increased postoperative complications and higher

Table 1 Participant's characteristics

\begin{tabular}{|c|c|c|c|c|}
\hline \multicolumn{2}{|c|}{ Demographic and clinical variables } & \multirow{2}{*}{$\begin{array}{l}\text { Simultaneous bilateral TKR }(n=50) \\
61.8(9.2)\end{array}$} & \multirow{2}{*}{$\begin{array}{l}\text { Unilateral TKR }(n=30) \\
65.7(9.4)\end{array}$} & \multirow{2}{*}{$\begin{array}{l}p \text {-value } \\
0.075\end{array}$} \\
\hline Age (years) & & & & \\
\hline \multirow[t]{2}{*}{ Gender } & Male & $18(36 \%)$ & $11(37 \%)$ & \multirow[t]{2}{*}{0.952} \\
\hline & Female & $32(64 \%)$ & $19(63 \%)$ & \\
\hline Weight $(\mathrm{kg})$ & & $93.5(8.2)$ & $96.1(5.5)$ & 0.014 \\
\hline \multirow[t]{3}{*}{ VAS } & Day 0 & $8.9(1.0)$ & $8.8(1.1)$ & 0.908 \\
\hline & Day 7 & $4.3(1.5)$ & $4.6(1.5)$ & 0.375 \\
\hline & Day 30 & $2.2(1.3)$ & $2.0(1.5)$ & 0.526 \\
\hline \multirow[t]{3}{*}{ LEFS } & Day 0 & $16.2(10.1)$ & $19.1(9.1)$ & 0.191 \\
\hline & Day 7 & $28.6(11.5)$ & $30.2(12.8)$ & 0.573 \\
\hline & Day 30 & $55.6(14.6)$ & $56.7(15.8)$ & 0.755 \\
\hline
\end{tabular}

TKR Total knee replacement; VAS Visual analog scale $(0-10 \mathrm{~cm})$; LEFS Lower extremity functional scale (0-80); Data are mean (Standard deviation) 
Table 2 Comparison of VAS and LEFS scores in two groups

\begin{tabular}{|c|c|c|c|c|c|}
\hline & & Simultaneous bilateral TKR $(n=50)$ & Unilateral TKR $(n=30)$ & $\mathrm{F}$ & $p$-value \\
\hline \multirow[t]{5}{*}{ VAS } & Day 0 & $8.9(1.0)$ & $8.8(1.1)$ & 0.032 & 0.859 \\
\hline & Day 7 & $4.3(1.5)$ & $4.6(1.5)$ & & \\
\hline & Day 30 & $2.2(1.3)$ & $2.0(1.5)$ & & \\
\hline & Change & 6.7 & 6.8 & 0.65 & 0.522 \\
\hline & $P$-value (intra group) & $<0.001$ & & & \\
\hline \multirow[t]{5}{*}{ LEFS } & Day 0 & $16.2(10.1)$ & $19.1(9.1)$ & 0.59 & 0.447 \\
\hline & Day 7 & $28.6(11.5)$ & $30.2(12.8)$ & & \\
\hline & Day 30 & $55.6(14.6)$ & $56.7(15.8)$ & & \\
\hline & Change & -39.4 & -37.6 & 0.27 & 0.765 \\
\hline & $P$-value (intra group) & $<0.001$ & & & \\
\hline
\end{tabular}

TKR Total knee replacement; VAS Visual analog scale $(0-10 \mathrm{~cm})$; LEFS Lower extremity functional scale (0-80); Data are mean (Standard deviation)

rehabilitation costs, in patients undergoing bilateral TKR than unilateral TKR $[9,34,35,9,37,38]$.

Recently, a study reported that bilateral simultaneous unicompartmental knee arthroplasty shows better functional recovery at 6 month post-operatively than unilateral TKR [36, 39]. However, a direct comparison could not be made as many methodological differences existed between previous and current study. First, previous study compared bilateral simultaneous unicompartmental knee arthroplasty with unilateral TKR; in contrast, the current study compared bilateral simultaneous TKR with unilateral TKR. Second, previous study compared outcome at 6 months postoperatively, in contrast, the current study compared outcome at 1 month postoperatively.

TKR is most common and successful surgical intervention to reduce pain and improve function in patients with end stage osteoarthritis [37, 38, 29, 30]. There are many factors should be considered before deciding surgical intervention such as patient's age, severity, symptom duration, pre-operative medical condition, and unilateral or bilateral involvement [31, 39]. The commonest indications for TKR include OA, traumatic arthritis and rheumatoid arthritis [31, 39].

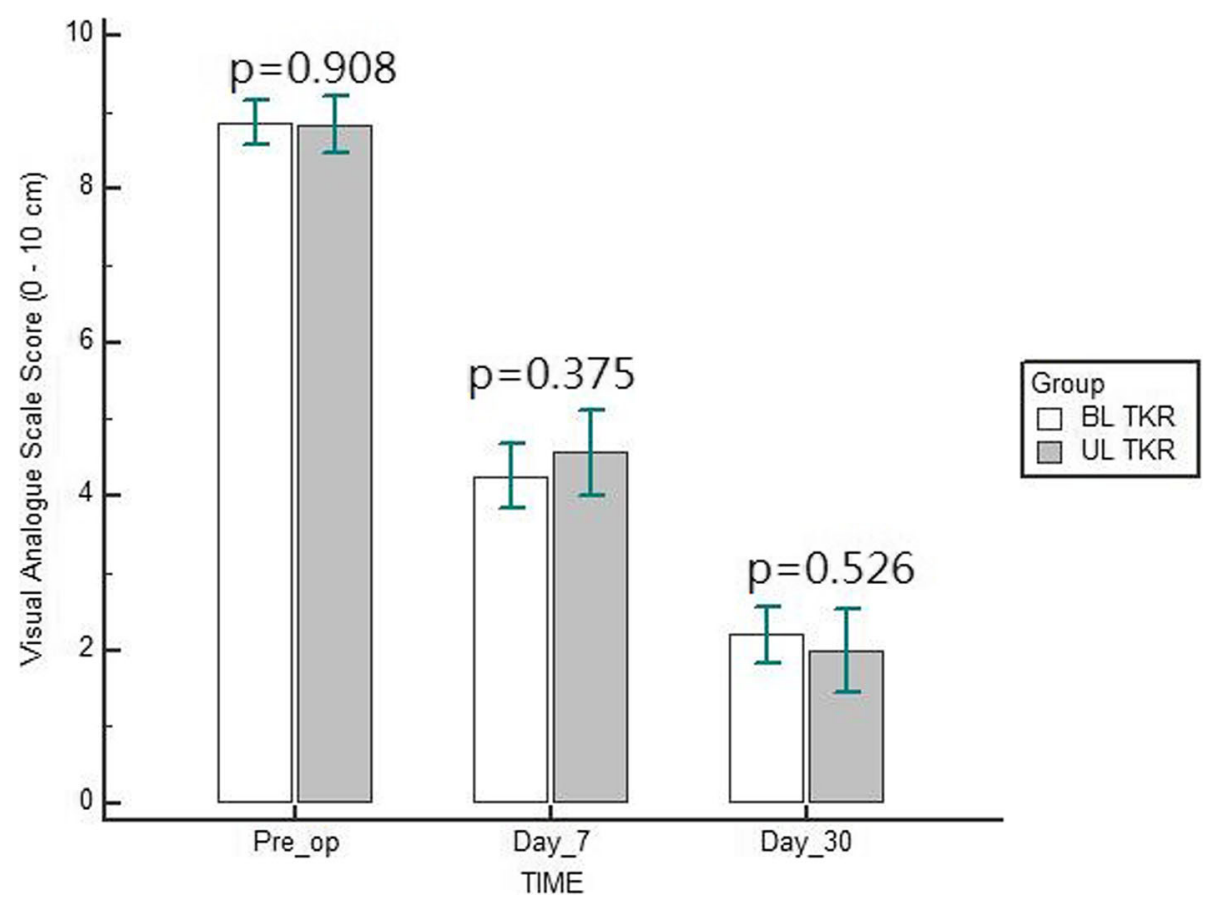

Fig. 1 Comparison of visual analogue scale score between simultaneous bilateral and unilateral total knee replacement (TKR) 


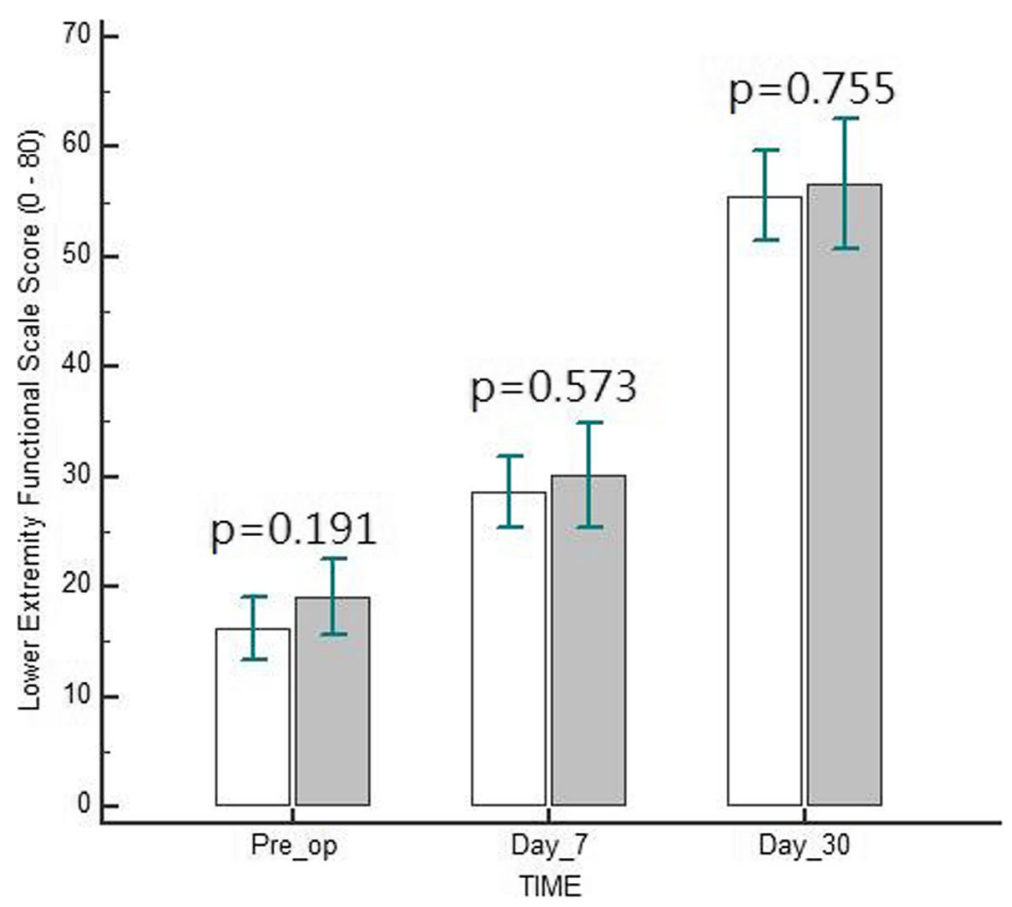

Fig. 2 Comparison of lower extremity functional scale score between simultaneous bilateral and unilateral total knee replacement (TKR)

In the current study, all patients had a diagnosis of primary knee OA.

It has been recommended that patients undergo simultaneous bilateral TKR surgery had a prolong rehabilitation, increased length of hospital stay, higher blood transfusion, increased number of painful postoperative days, a greater number of complications, and increased financial burden [31, 39]. Nonetheless, these parameters have been showed significantly better than in those patients undergo staged arthroplasty surgery [13, 18, 40]. Although several studies indicated that postoperative medical complications often seen in patients undergo simultaneous bilateral TKR surgery [41-43], other studies indicated similar complication rates $[44,45]$.

It is well established that TKR reduces knee pain and improves physical function in patients with knee OA. In line with previous studies, the current study reported reduced pain intensity and improved physical function in both simultaneous bilateral or unilateral TKR groups. The changes in pain intensity and physical function were statistically and clinically significant and were greater than reported minimally clinical important difference [46-48]. The current study reported a higher reduction in pain intensity in both groups than previous study (75\% versus $47 \%$ ) [49]. In contrast to previous study, simultaneous bilateral TKR group reported little higher functional improvement than unilateral TKR group (71\% versus 66\%) in the current study [49]. However, there were some methodological differences exists between current and former study. Number of simultaneous bilateral TKR group was large (63\% versus $27 \%)$ in the current study while in the previous study unilateral TKR group was large (69\% versus $31 \%$ ). Additionally, previous study used the Western Ontario McMaster universities osteoarthritis index while the current study used LEFS to assess physical function.

The current study has several potential limitations. In the current study, physical function was assessed using LEFS, which is a subjective self-report functional scale. An objective outcome measure could be included to assess wide range of physical function. For instance, various performance based outcome measures such as timed up and go test and stair climbing test could be used to better understand functional recovery in these population. Additionally, the current study only assessed pain and function. Other important outcome measures such as ambulation, muscle strength, mobility, range of motion, and quality of life are warranted to consider in future study. The result of this study was restricted to simultaneous bilateral or unilateral TKR in patient with end stage $\mathrm{OA}$, and therefore it might limit the generalizability of findings to other types of replacement surgeries. Additionally, the current study compared simultaneous bilateral TKR with a single unilateral TKR instead a staged bilateral TKR. Therefore, randomized controlled studies are warranted to further identify the differences in the various outcomes between simultaneous and staged bilateral TKR. Moreover, future study 
may investigate the effect of physiotherapy intervention to reduce post-operative complications and improve functional outcomes after simultaneous bilateral or unilateral TKR.

\section{Conclusions}

Simultaneous bilateral TKR was associated with similar reduction of pain intensity and recovery of function compare to unilateral TKR, suggesting the use of simultaneous bilateral TKR in patients with bilateral knee osteoarthritis since its costs and rehabilitation process could be reduced compared to staged bilateral TKR.

\section{Abbreviations}

TKR: Total knee replacement; VAS: Visual analogue scale; LEFS: Lower extremity functional scale; OA: Osteoarthritis

\section{Acknowledgments}

The authors are grateful to the Deanship of Scientific Research, King Saud University for funding through Vice Deanship of Scientific Research Chairs.

\section{Author contributions}

SA: corresponding author, participated in the study design, participated in the data collection, drafted the manuscript, and finalized the manuscript. AA: participated in the study design, helped with the ethics application and revised the manuscript critically. ZAl: participated in the study design, participated in the data collection, and revised the manuscript critically. DA participated in the study design, participated in the data collection, and revised the manuscript critically. All authors read and approved the final manuscript.

\section{Funding}

The Deanship of Scientific Research, King Saud University provides funding through Vice Deanship of Scientific Research Chairs. The funding body played no role in the study design, writing of the manuscript, or decision to submit the manuscript for publication.

\section{Availability of data and materials}

All data generated or analyzed during this study are presented in the manuscript. Please contact the corresponding author for access to data presented in this study.

\section{Ethics approval and consent to participate}

The present study was approved by the local ethics committee of the Rehabilitation Research Chair, King Saud University. A written informed consent was taken from each patient.

\section{Consent for publication}

Not Applicable.

\section{Competing interests}

Shahnawaz Anwer is a member of the editorial board of BMC

Musculoskeletal Disorders journal. No other conflicts of interest, financial or otherwise, are declared by the author(s)

\section{Author details}

${ }^{1}$ Rehabilitation Research Chair, College of Applied Medical Sciences, King Saud University, P.O.Box-10219, -11433, Riyadh, Saudi Arabia. ${ }^{2}$ Department of Building and Real Estate, Hong Kong Polytechnic University, Kowloon, Hong Kong Special Administrative Region, Hong Kong. ${ }^{3}$ Bone Joint and Trauma Clinic, Darbhanga, India. ${ }^{4}$ Royal Hospital and Trauma Center, Darbhanga, India.
Received: 23 September 2019 Accepted: 3 April 2020

Published online: 15 April 2020

\section{References}

1. Rodriguez JA, Bhende H, Ranawat CS. Total condylar knee replacement: a 20-year followup study. Clin Orthop. 2001;388:10-7.

2. Gill GS, Joshi AB, Mills DM. Total condylar knee arthroplasty. 16- to 21-year results. Clin Orthop. 1999;367:210-5.

3. Thadani PJ, Vince KG, Ortaaslan SG, Blackburn DC, Cudiamat CV. Ten- to 12year followup of the Insall-Burstein I total knee prosthesis. Clin Orthop. 2000; 380:17-29.

4. Worland RL, Johnson GV, Alemparte J, Jessup DE, Keenan J, Norambuena N. Ten to fourteen-year survival and functional analysis of the AGC total knee replacement system. Knee. 2002;9:133-7.

5. Yoon $\mathrm{HS}$, Han $\mathrm{CD}$, Yang $\mathrm{H}$. Comparison of simultaneous bilateral and staged bilateral total knee arthroplasty in terms of perioperative complications. J Arthroplast. 2010;25(2):179-85.

6. McMahon M, Block JA. The risk of contralateral total knee arthroplasty after knee replacement for osteoarthritis. J Rheumatol. 2003;30(8):1822-4.

7. Memtsoudis SG, Hargett M, Russell LA, Parvizi J, Cats-Baril WL, Stundner O, et al. Consensus statement from the consensus conference on bilateral total knee arthroplasty group. Clin Orthop Relat Res. 2013:471:2649-57.

8. Meehan JP, Danielsen B, Tancredi DJ, Kim S, Jamali AA, White RH. A population-based comparison of the incidence of adverse outcomes after simultaneous-bilateral and staged-bilateral total knee arthroplasty. J Bone Joint Surg Am. 2011:93:2203-13.

9. Restrepo C, Parvizi J, Dietrich T, Einhorn TA. Safety of simultaneous bilateral total knee arthroplasty. A meta-analysis. J Bone Joint Surg Am. 2007;89: 1220-6.

10. Fu D, Li G, Chen K, Zeng H, Zhang X, Cai Z. Comparison of clinical outcome between simultaneous-bilateral and staged-bilateral total knee arthroplasty: a systematic review of retrospective studies. J Arthroplast. 2013;28:1141-7.

11. Odum SM, Troyer JL, Kelly MP, Dedini RD, Bozic KJ. A cost-utility analysis comparing the cost-effectiveness of simultaneous and staged bilateral total knee arthroplasty. JBJS. 2013:95(16):1441-9.

12. Reuben JD, Meyers SJ, Cox DD, Elliott M, Watson M, Shim SD. Cost comparison between bilateral simultaneous, staged, and unilateral total joint arthroplasty. J Arthroplast. 1998;13(2):172-9.

13. Macario A, Schilling P, Rubio R, Goodman S. Economics of one-stage versus two-stage bilateral total knee arthroplasties. Clin Orthop Relat Res. 2003;414: 149-56.

14. Jain S, Wasnik S, Mittal A, Sohoni S, Kasture S. Simultaneous bilateral total knee replacement: a prospective study of 150 patients. J Orthop Surg (Hong Kong). 2013:21(1):19.

15. Gabr A, Withers D, Pope J, Santini A. Functional outcome of staged bilateral knee replacements. Ann R Coll Surg Engl. 2011:93(7):537.

16. Hart A, Antoniou J, Brin YS, Huk OL, Zukor DJ, Bergeron SG. Simultaneous bilateral versus unilateral total knee arthroplasty: a comparison of 30-day readmission rates and major complications. J Arthroplast. 2016;31(1):31-5.

17. Borges JH, Lobo Júnior P, Dias DM, Silva MF, Freitas A, Araúijo T. Cost and safety evaluation of simultaneous bilateral Total knee Arthroplasty versus unilateral knee. Rev Bras Ortop (Sao Paulo). 2019;54(6):709-13.

18. March LM, Cross M, Tribe KL, Lapsley HM, Courtenay BG, Cross MJ, et al. Two knees or not two knees? Patient costs and outcomes following bilateral and unilateral total knee joint replacement surgery for OA. Osteoarthr Cartil. 2004;12(5):400.

19. Bagsby D, Pierson JL. Functional outcomes of simultaneous bilateral versus unilateral total knee arthroplasty. Orthopedics. 2015;38(1):e43-7.

20. Huang $\mathrm{YH}$, Lin $\mathrm{C}$, Yang JH, Lin LC, Mou CY, Chiang KT, et al. No difference in the functional improvements between unilateral and bilateral total knee replacements. BMC Musculoskelet Disord. 2018;19(1):87.

21. Frueh $W$, Sharkey P. The standard anterior medial Parapatellar approach to TKA. In: Minimally invasive Total joint Arthroplasty. Berlin, Heidelberg: Springer; 2004. p. 132-8

22. Luedtke-Hoffmann KA, Schafer DS. Pulsed lavage in wound cleansing. Phys Ther. 2000:80(3):292-300

23. Kharat K. Closure in knee replacement surgery. J Orthop Case Rep. 2012;2(3):31.

24. Gallasch CH, Alexandre NM. The measurement of musculoskeletal pain intensity: a comparison of four methods. Rev Gaucha Enferm. 2007:28(2): 260-5. 
25. Jensen MP, Karoly P. Self-report scales and procedures for assessing pain in adults. In: Turk DC, Melzack R, editors. Handbook of pain assessment. New York: NY, Guilford Press; 2011. p. 19-44.

26. Hjermstad MJ, Fayers PM, Haugen DF, Caraceni A, Hanks GW, Loge JH, et al. Studies comparing numerical rating scales, verbal rating scales, and visual analogue scales for assessment of pain intensity in adults: a systematic literature review. J Pain Symptom Manag. 2011;41:1073-93.

27. Watson CJ, Propps M, Ratner J, Zeigler DL, Horton P, Smith SS. Reliability and responsiveness of the lower extremity functional scale and the anterior knee pain scale in patients with anterior knee pain. J Orthop Sports Phys Ther. 2005;35(3):136-46.

28. Pua YH, Cowan SM, Wrigley TV, Bennell KL. The lower extremity functional scale could be an alternative to the Western Ontario and McMaster universities osteoarthritis index physical function scale. J Clin Epidemiol. 2009;62(10):1103-11.

29. Zeni JA Jr, Snyder-Mackler L. Clinical outcomes after simultaneous bilateral total knee arthroplasty: comparison to unilateral total knee arthroplasty and healthy controls. J Arthroplast. 2010;25(4):541-6.

30. Horne G, Devane P, Adams K. Complications and outcomes of single-stage bilateral total knee arthroplasty. ANZ J Surg. 2005;75(9):734-8.

31. Ritter MA, Harty LD. Debate: simultaneous bilateral knee replacements: the outcomes justify its use. Clin Orthop Relat Res. 2004;428:84-6.

32. Jenny JY, Trojani C, Prudhon JL, Vielpeau C, Saragaglia D, Houillon C, et al. Simultaneous bilateral total knee arthroplasty. A multicenter feasibility study. Orthop Traumatol Surg Res. 2013;99(2):191-5.

33. Powell RS, Pulido P, Tuason MS, Colwell CW Jr, Ezzet KA. Bilateral vs unilateral total knee arthroplasty: a patient-based comparison of pain levels and recovery of ambulatory skills. J Arthroplast. 2006;21(5):642-9.

34. Ritter MA, Harty LD, Davis KE, Meding JB, Berend M. Simultaneous bilateral, staged bilateral, and unilateral total knee arthroplasty. A survival analysis. J Bone Joint Surg Am. 2003;85-A(8):1532-7.

35. Luscombe JC, Theivendran $\mathrm{K}$, Abudu A, Carter SR. The relative safety of onestage bilateral total knee arthroplasty. Int Orthop. 2009;33(1):101-4.

36. Ahn JH, Kang DM, Choi KJ. Bilateral simultaneous unicompartmental knee arthroplasty versus unilateral total knee arthroplasty: a comparison of the amount of blood loss and transfusion, perioperative complications, hospital stay, and functional recovery. Orthop Traumatol Surg Res. 2017;103(7):1041-5.

37. Varacallo M, Luo TD, Johanson NA. Total Knee Arthroplasty (TKA) Techniques. [Updated 2019 Dec 17]. In: StatPearls [Internet]. Treasure Island (FL): StatPearls Publishing; 2020 Jan-. Available from: https://www.ncbi.nlm. nih.gov/books/NBK499896/.

38. Feng JE, Novikov D, Anoushiravani AA, Schwarzkopf R. Total knee arthroplasty: improving outcomes with a multidisciplinary approach. J Multidiscip Healthc. 2018;11:63

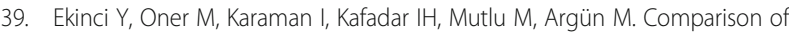
simultaneous bilateral with unilateral total knee arthroplasty. Acta Orthop Traumatol Turc. 2014;48(2):127-35.

40. Bullock DP, Sporer SM, Shirreffs TG Jr. Comparison of simultaneous bilateral with unilateral total knee arthroplasty in terms of perioperative complications. J Bone Joint Surg Am. 2003;85-A:1981-6.

41. Noble J, Goodall JR, Noble DJ. Simultaneous bilateral total knee replacement: a persistent controversy. Knee. 2009;16:420-6.

42. Barrett J, Baron JA, Losina E, Wright J, Mahomed NN, Katz JN. Bilateral total knee replacement: staging and pulmonary embolism. J Bone Joint Surg Am. 2006;88:2146-51.

43. Oakes DA, Hanssen AD. Bilateral total knee replacement using the same anesthetic is not justified by assessment of the risks. Clin Orthop Relat Res. 2004:428:87-91.

44. Choi YJ, Lee HI, Ra HJ, Hwang DY, Kim TK, Shim SJ. Perioperative risk assessment in patients aged 75 years or older: comparison between bilateral and unilateral total knee arthroplasty. Knee Surg Relat Res. 2014 Dec;26(4):222

45. Hersekli MA, Akpinar S, Ozalay M, Ozkoç G, Uysal M, Cesur N, et al. A comparison between single- and two-staged bilateral total knee arthroplasty operations in terms of the amount of blood loss and transfusion, perioperative complications, hospital stay, and costeffectiveness. [Article in Turkish. Acta Orthop Traumatol Turc. 2004;38:241-6.

46. Tubach F, Ravaud P, Baron G, Falissard B, Logeart I, Bellamy N, et al. Evaluation of clinically relevant changes in patient reported outcomes in knee and hip osteoarthritis: the minimal clinically important improvement. Ann Rheum Dis. 2005;64(1):29-33.
47. van der Wees PJ, Wammes JJ, Akkermans RP, Koetsenruijter J, Westert GP, van Kampen A, et al. Patient-reported health outcomes after total hip and knee surgery in a Dutch University hospital setting: results of twenty years clinical registry. BMC Musculoskelet Disord. 2017;18(1):97.

48. Mehta SP, Fulton A, Quach C, Thistle M, Toledo C, Evans NA. Measurement properties of the lower extremity functional scale: a systematic review. J Orthop Sports Phys Ther. 2016;46(3):200-16.

49. Kim JH, Kim BR, Kim SR, Han EY, Nam KW, Lee SY, Kim WB. Functional outcomes after critical pathway for inpatient rehabilitation of total knee arthroplasty. Ann Rehabil Med. 2019;43(6):650-61.

\section{Publisher's Note}

Springer Nature remains neutral with regard to jurisdictional claims in published maps and institutional affiliations.
Ready to submit your research? Choose BMC and benefit from:

- fast, convenient online submission

- thorough peer review by experienced researchers in your field

- rapid publication on acceptance

- support for research data, including large and complex data types

- gold Open Access which fosters wider collaboration and increased citations

- maximum visibility for your research: over $100 \mathrm{M}$ website views per year

At BMC, research is always in progress.

Learn more biomedcentral.com/submissions 